\title{
El transhumanismo de Paul B. Preciado: Sobre las ficciones antirrealistas del Manifiesto contrasexual
}

\section{The Transhumanism of Paul B. Preciado: On the Antirealist Fictions of Contrasexual Manifiesto}

\author{
María J. Binetti* \\ Conicet / Instituto de Investigaciones de Estudios de Género \\ de la Universidad de Buenos Aires, Argentina \\ mjbinetti@gmail.com \\ ORCID: 0000-0003-1850-6408 \\ Valentina Cruz** \\ Universidad de Buenos Aires, Argentina \\ valentinacruzfv@gmail.com

\section{Daniel Alberto Sicerone ${ }^{* * *}$} \\ CONicet / Instituto de Investigaciones de Estudios de Género \\ de la Universidad de Buenos Aires, Argentina \\ siceroned@gmail.com \\ ORCID: 0000-0002-5401-1720
}




\title{
Resumen
}

En este artículo se propone un análisis crítico de algunos de los principales relatos que sostienen la narrativa postqueer de Paul-Beatriz Preciado, partiendo del supuesto de que toda identidad sexual es una ficción y toda realidad, una construcción psico-social. Mostraremos el modo en que la ficcionalidad biopolítica y el constructivismo trans-humanista del autor borran la consistencia ontológica de lo real, lo irreductible de la diferencia sexual, a la mujer como sujeto político del feminismo y, en última instancia, al feminismo como proyecto político emancipatorio.

Palabras ClaVe: constructivismo, socio-lingüística, materia, poscuerpo, género.

\begin{abstract}
The current article aims at a critical analysis of some of the main tales around which Paul B. Preciado develops his post-queer political narrative, based on the assumption that all sexual identity is fiction and all reality a psycho-social construction. We will try to show the way in which the bio-political fiction and trans-humanist constructivism of the author erase the ontological consistency of the real, the irreducibility of sexual difference, the woman as the political subject of feminism, and ultimately feminism itself as an emancipatory political project.
\end{abstract}

KeYwORDs: Constructivism, socio-linguisticism, matter, post-body, gender.

Recepción 12-08-20 / Aceptación 09-02-21 
* Doctora en Filosofía por la Universidad de Navarra (2004), magíster en Estudios de las mujeres y de género por la Universidad de Luján (2018), investigadora del CONICET con sede en el Instituto Interdisciplinario de Estudios de Género (Universidad de Buenos Aires), y profesora de grado y posgrado en diversas universidades. Actualmente desarrolla su actividad en torno a una filosofía feminista de la diferencia sexual, matricial y material, conceptualizada en el marco de los nuevos realismos materiales. Entre sus libros destacan Mater/realismo. Aportes para una filosofía feminista de la diferencia sexual (Buenos Aires: Prometeo, 2018), El idealismo de Kierkegaard (Ciudad de México: Universidad Iberoamericana, 2015), El poder de la libertad. Introducción a Kierkegaard (Buenos Aires: Ciafic Ediciones, 2006). Es además traductora de la obra de Kierkegaard del danés y ha publicado numerosos artículos en revistas internacionales.

** Profesora de Filosofía en la Universidad de Buenos Aires, licenciada en Psicología por la Universidad Kennedy (Buenos Aires), maestrante en Psicoanálisis (Universidad Nacional de Rosario), exdocente-investigadora de la Cátedra de Psicología fenomenológica y existencial (Facultad de Psicología-UbA).

*** Magíster Scientiarum en Filosofía por la Universidad del Zulia (Venezuela, 2016), licenciado en Filosofía por la Universidad Católica Cecilio Acosta (Venezuela, 2013), becario doctoral conicEt adscrito al Instituto de Filosofía Dr. Alejandro Korn de la Facultad de Filosofía y Letras de la UBA. Actualmente desarrolla una investigación doctoral sobre la relación entre la desontologización de la sexualidad y sus consecuencias políticas en el ámbito de la sexopolítica desarrollada por Paul B. Preciado. 


\section{Introducción}

El nominalismo posmoderno se asienta sobre el supuesto de que la realidad es reducible a signos lingüísticos, cadenas significantes, ficciones retóricas, construcciones y deconstrucciones históricas-culturales, performances y creaciones estéticas, productores de un postsujeto de índole socio-lingüística, que a su vez los re-producirá en juegos discursivos. Esto supone una concepción antropocéntrica, o mejor, androcéntrica y voluntarista de lo real, supeditada a la medida del hombre social. Tal argumento configura el punto de partida de la narrativa, o más bien, de la contra-narrativa posfeminista y post-queer de Paul B. Preciado, para quien las ficciones discursivas que producen la realidad son efectos de la maquinaria de poder social.

El pensamiento filosófico de Preciado se articula en el cruce de la filosofía postestructuralista de Michel Foucault y de la pareja editorial formada por Gilles Deleuze-Félix Guattari. Del primero retoma los estudios acerca de la sexualidad ${ }^{1}$ en tanto realidad transactiva, es decir, efecto de determinados dispositivos y mecanismos de poder cuya ficcionalidad cobra sentido en el horizonte de sus propias condiciones de posibilidad siempre socio-históricas. Respecto a Deleuze y Guattari, Preciado asume las consignas desterritorializantes y descodificantes del Anti-Edipo ${ }^{2}$ como corpus político de las autodenominadas minorías rizomáticas y nómadas. Vale la pena mencionar, además, las influencias menores del freudo-marxismo de Herbert Marcuse ${ }^{3}$ y la democracia anal de Guy Hocquenghem. ${ }^{4}$ Podríamos afirmar que el marco teórico de Preciado es

Michel Foucault, Historia de la sexualidad. La voluntad de saber (Buenos Aires: Siglo xxi Editores, 2014).

2 Gilles Deleuze y Félix Guattari, El Anti-Edipo. Capitalismo y esquizofrenia (Barcelona: Paidós, 2004).

Herbert Marcuse, Eros y civilización (Madrid: Sarpe, 1983).

Guy Hocquenghem, El deseo homosexual (Madrid: Melusina, 2009). 
claramente antropológico, en el sentido en que sitúa lo real en dependencia de la acción y locución humana, como el non plus ultra socio-político de toda realidad.

La filosofía de Preciado es resultado de las transformaciones tecno-políticas de la segunda mitad del siglo xx, especialmente de la lógica cultural que acompańa el modelo de producción capitalista en su versión neoliberal. Modulada por el neoliberalismo, la libertad abandona el espacio de las demandas colectivas para convertirse en una instancia de gestión individual y privada. En una sociedad donde el mercado no sólo rige las transacciones económicas, sino también los patrones culturales que la identifican, el carácter conflictivo de la alteridad se licúa en una diversidad potencialmente infinita, indeterminada e indecidible. De aquí que la diferencia misma pierda su carácter dialéctico y se reduzca a mera diversidad extrínseca, neutra y homogeneizante.

La teoría de Preciado es, en este sentido, hija predilecta del socio-lingüisticismo ${ }^{5}$ posmoderno y el mercado neoliberal, de ahí el carácter relativista y despolitizado de su pensamiento, que ha renunciado al potencial político de los movimientos queer de los ochenta y termina borrando al sujeto político del feminismo. En efecto, mientras que el activismo queer de los ochenta desplegó una serie de demandas que apuntaba a una transformación estructural de lo social; el individualismo queer de Preciado se parapeta en las políticas identitarias de grupos o individuos, que se proclaman diversos del resto y son incapaces de articular una consigna política estructural debido a su mismo relativismo y fragmentación identitaria.

Hablamos de socio-lingüisticismo en lugar de socio-lingüístico para subrayar la extrapolación ontológica y el uso reduccionista de la lingüística. La expresión se encuentra en Stacy Alaimo y Susan Hekman (eds.), Material Feminisms (Bloomington: Indiana University Press, 2008), 69. 
Las páginas que siguen proponen un análisis crítico sobre algunos de los principales relatos en torno a los cuales Preciado elabora su narrativa política antirrealista $y$, en cierto sentido, también antisocial. Dicho pensamiento elimina, en un mismo golpe de ficcionalidad biopolítica y constructivismo androcéntrico, la consistencia ontológica de lo real, lo irreductible de la diferencia sexual, a la mujer como sujeto política del feminismo y, a la postre, a feminismo como proyecto de transformación estructural. Producto de este análisis, intentaremos algunas elaboraciones críticas basadas en el giro neo-realista como superador de la disolución antirrealista, antisocial y antifeminista en donde desemboca el transhumanismo ficcional de Paul B. Preciado, en particular, y la metanarrativa posmoderna, en general.

\section{La propuesta del Manifiesto contrasexual}

En su Manifiesto contrasexual, ${ }^{6}$ Preciado nos propone un nuevo régimen social capaz de reorganizar los despojos de la sociedad sexual que todavía habitamos y es preciso abandonar, basada en la hetero-normatividad como sistema de control. El quid de la cuestión, eso que lo ha obsesionado y contra lo que no ha cesado de luchar, tanto en la teoría como en la relación práctica con su propio cuerpo, es la diferencia sexual entendida no sólo en los términos hetero-normativos de la teoría queer, sino, además, en tanto determinación encarnada constitutiva de su propia realidad material. Recordemos que, en una primera aproximación realista, se entiende por diferencia sexual un dinamismo determinante y constitutivo de la persona humana que incide en todos sus niveles y ámbitos de reali-

6 Paul B. Preciado, Manifiesto contrasexual. Prácticas subversivas de identidad sexual (Madrid: Ópera Prima, 2002). 
zación. Desde el punto de vista científico-natural, la diferencia sexual es además una característica evolutiva y reproductiva del mundo animal y vegetal, a partir de la cual la vida misma logra la máxima diversificación y variación posible. Para la narrativa queer, sin embargo, tal determinación material y evolutiva se reduce a una norma de comportamiento socio-político que opera como dispositivo de control subjetivo y que, definitivamente, es necesario eliminar. El proyecto contra-sexual de Preciado supone una nueva forma de reproducción, evolución y existencia propiamente trans-genérica, trans-humana y tecno-sexual.

Preciado interpreta el binarismo sexual —específico de la función reproductiva - como efecto del dualismo socio-político de los géneros. El binarismo sexual es producto del disciplinamiento hetero-normativo al cual son sometidos los sujetos discursivos. Ahora bien, la misma norma que ordena a algunos cuerpos, excluye a otros y los dispone en los márgenes del sistema sexual. Estos últimos son los portadores de anormalidades y abyecciones sexuales, considerando como anormal mutaciones genéticas o epigéneticas, atrofias, síndromes, malformaciones, alteraciones en el desarrollo físico, así como elecciones de diversos objetos sexuales o prácticas parafílicas tales como sadomasoquismo, zoofilia, necrofilia, coprofilia, coprofagia, urofilia, pedofilia, travestismo o transexualismo, entre muchas otras. La heterosexualidad — esto es, la diferencia sexuales el criterio de medida a partir del cual tales cuerpos o prácticas son excluidos y tenidos por abyectos, razón por la que debe abolirse a fin de que éstos sean liberados. Esta abolición radical resume el proyecto teórico-político de Preciado.

Lo interesante y transgresor de su propuesta es que no se reduce a la inclusión social o ética-política de los sujetos previamente marginados, sino que va mucho más allá y se define por una inversión significante que coloca lo abyecto como medida, o mejor, como sin-medida de toda subjetividad, reduciendo los cuerpos a una suerte de hibridez asexual a partir de la cual diversificarse a voluntad. No se trata sólo de eliminar el 
sentido normativo, jerárquico y disciplinario de los géneros socialmente construidos, sino de deconstruir la materialidad de los cuerpos sexuados, a fin de convertirlos en somatecas ${ }^{7}$ o artefactos tecnológicos. En la sociedad contrasexual, los cuerpos cuentan sólo por un órgano que los iguala y nivela, a saber, el ano. El principio del ano, dispuesto como centro universal de igualdad e intercambio, supera la subordinación y dominación implícita en los heterosexuales vagina-pene.

La equivalencia posmoderna entre ficción imaginaria y realidad, o bien entre discurso cultural y sexualidad bio-psíquica, adquiere en Preciado la consistencia de una arquitectura de diseño. Los cuerpos se construyen por agregados de partes y miembros, se manipulan cual materia bruta a disposición del arquitecto/dueño en turno. De este modo, en la sociedad contrasexual es posible "tener pene y clítoris o ninguna de las dos cosas, o un tercer brazo en lugar de un pene, un clítoris en el medio del plexo solar o una oreja erotizada destinada al placer auditivo". ${ }^{8}$ Todo es posible con sólo quererlo y fabricarlo.

La promoción del cuerpo anal y su arquitectura de diseño exige, además, una nueva legalidad jurídica enmarcada en el nuevo manifiesto social que Preciado ofrece. Los sujetos contrasexuados deberán firmar un contrato mediante el cual renuncien a todas las prácticas o identificaciones sexuales del viejo régimen heteronormativo. Su primera cláusula declara de manera pública y vinculante la abdicación voluntaria a la diferencia sexual en los siguientes términos:

Yo ........ renuncio a mi condición natural de hombre o de mujer, a todo privilegio (social, económico, patrimonial) y a toda obligación (social, eco-

Preciado denomina "somatecas" a los cuerpos producidos mediante complejas tecnologías y recursos farmacológicos.

8 Paul B. Preciado, Un apartamento en Urano. Crónicas del cruce (Barcelona: Anagrama, 2019), 250. 
nómica, reproductiva) derivados de mi condición sexual en el marco del sistema hetero-centrado naturalizado. Me reconozco y reconozco a los otros como cuerpos parlantes y acepto, de pleno consentimiento, no mantener relaciones sexuales naturalizantes, ni establecer relaciones sexuales fuera de contratos contrasexuales temporales y consensuados [...] Renuncio a todos los lazos de filiación (maritales o parentales) [...] Renuncio a todos mis derechos de propiedad sobre mis flujos seminales o producciones de mi útero. ${ }^{9}$

Lo único irrenunciable e irreducible es la disposición discursiva del sujeto, de cuyo performances lingüísticos emergerán todas las cosas. A esta renuncia fundacional le suceden otras trece cláusulas contrasexuales que prohíben el retorno a la heterosexualidad natural y su normalización a través del matrimonio, la familia nuclear, la maternidad y paternidad individuales, la escuela y sus currículos, la medicina, la religión, etcétera. Respecto a la reproducción de la especie, la propuesta de Preciado consiste en la colectivización de los fluidos seminales y úteros, ${ }^{10}$ de manera tal que la familia nuclear como célula de producción, reproducción y consumo sea abolida. Su proyecto incluye la creación de centros universitarios destinados a la enseñanza y aprendizaje de diversas disciplinas contrasexuales, por ejemplo, prácticas sadomasoquistas y fetichistas que resignifiquen radicalmente el erotismo humano.

Preciado se preocupa por precisar que su propuesta no se reduce a la emancipación sexual de gays y lesbianas al estilo de los movimientos de la década de 1960, o a la liberación de los cuerpos y energías de la opresión social. Tampoco debe entenderse como una demanda de minorías sexuales por una ampliación de derechos, sino como una nueva sexuación universal que se sacuda de encima el discurso y las instituciones

Preciado, Manifiesto, 37.

10 Preciado, Un apartamento, 41. 
del sistema sexo-género heteronormativo. Lo innovador radica entonces en la producción de los cuerpos mismos y sus prácticas, por fuera de la diferencia sexual. A esta producción Preciado la denomina contra-sexual y la describe de este modo:

El nombre de contrasexualidad proviene indirectamente de Foucault, para quien la forma más eficaz de resistencia a la producción disciplinaria de la sexualidad en nuestras sociedades liberales no es la lucha contra la prohibición (como la propuesta por los movimientos de liberación sexual anti-represivos de los años setenta), sino la contra-productividad, es decir, la producción de formas de placer-saber alternativas a la sexualidad moderna. Las prácticas contrasexuales que van a proponerse aquí deben comprenderse como tecnologías de resistencia, dicho de otra manera, como formas de contra-disciplina sexual. ${ }^{11}$

A fin de justificar su nuevo régimen social, Preciado intenta justificar el carácter radicalmente indeterminado y omnipotencial de la materialidad poscuerpo. Siguiendo el modelo de cuerpos sin órganos de Deleuze y Guattari, sostiene que "los órganos sexuales como tales no existen. Los órganos que reconocemos como naturalmente sexuales son ya el producto de una tecnología sofisticada que prescribe el contexto en el que los órganos adquieren su significación". ${ }^{12}$ Sin órganos ni estratos, el nuevo poscuerpo se parece a una tabula rasa en la cual todo está por escribirse y construir. La fuerza posibilitante de esta tarea omniconstructiva es lo que Preciado denomina potentia gaudendi: ${ }^{13}$ una suerte de contra-pulsión fundamental, completamente indeterminada, cuya actualización obede-

11 Preciado, Manifiesto, 19.

12 Preciado, Manifiesto, 26-27.

13 Paul B. Preciado, Testo Yonqui (Madrid: Espasa Calpe, 2008), 38 ss. 
ce al principio del goce. A diferencia del principio sexual del placer, el goce no tiene medida ni finalidad, él opera — para decirlo con Freud— más allá del principio del placer.

Las tecnologías del goce están diseñadas para hacer corresponder un dildo - o simulacro- con un orificio - o simulacro- - preferentemente el ano. La fórmula de su goce es propiamente "dildo+X". A diferencia del primado del falo, en torno al cual se organiza el falogocentrismo clásico y sus placeres, Preciado afirma la primacía del dildo y sus goces. El primer supuesto de su erótica asegura que en "el principio era el dildo", ${ }^{14}$ y a su fuerza de penetración remite cualquier goce contrasexual. Algunas tecnologías reproducen los roles de subordinación pasivo-activo — como el sadomasoquismo o el fist fucking - , otras producen igualdad, entendida como posiciones sexuales intercambiables. El ano como centro de pene-tración contrasexual abole las categorías sexuales tradicionales y supera la subordinación de un sexo a otro. Gracias a él, ya no hay nadie exclusivamente activo o pasivo, sino que todos somos capaces de asumir roles intercambiables. Se alcanza así una suerte de verdadera igualdad/ equivalencia entre los sujetos parlantes, que supera las estructuras patriarcales y el sistema sexo/género en juego desde hace miles de años, aunque en el camino hemos perdido todo menos el ano. Conforme con la democracia anal,

el dildo convierte el follar [...] en un acto paradójico al no poder ser identificado como órgano en la oposición tradicional hombre/activo o mujer/pasiva. Confrontada a este pequeño objeto, la totalidad del sistema heterosexual de los roles de género pierde su sentido. ${ }^{15}$

14 Preciado, Manifiesto, 19-20.

15 Preciado, Manifiesto, 69. 
Y si acaso dildos y anos se mostraran insuficientes, también contamos con los puños y los brazos, porque para la lógica contrasexual hay un pene contenido en cada brazo y siempre bien dispuesto a un fisting bestial. ${ }^{16}$ En síntesis, las tecnologías contrasexuales nos proponen un modelo omnipotente, donde el sujeto parlante será a la vez penetrado y penetrador, sobre todo aquel dotado a la vez de pene-ano.

\section{Los supuestos desontologizantes $\mathrm{y}$ antirrealistas del proyecto contrasexual}

El breve recorrido trazado hasta aquí nos permite dilucidar algunos supuestos sobre los cuales descansa la propuesta contrasexual de Preciado. El primero de ellos reside en la desontologización radical de la realidad en su conjunto, reducida a ficciones discursivas de origen socio-político, y de la diferencia sexual en particular, convertida en praxis hetero-normativa. Preciado se pronuncia abiertamente contra todo intento de ontologización por considerarlo radicalmente incompatible con su propuesta. Ahora bien, ¿qué rechaza cuando dice rechazar la ontología?

Lo que Preciado entiende por ontología sería como una parodia o simulacro ontológico: una suerte de mundo feliz, de idealidades o esencias plenas, perfectas y eternas, que constituirían el modelo inmutable del pobre mundo finito. El relato de Preciado caricaturiza la ontología como una totalidad trascendente y fija, que pautaría ella misma el destino de la temporalidad. La ironía del autor es hacer pasar esta parodia por ontología sin más, a lo cual se suma la falacia de interpretar ese modelo ontológico como el opuesto excluyente de la relatividad y la contingencia finita. Preciado instala así una opción dualista entre un sustancialismo

16 Ver Preciado, Testo Yonqui, 291 y Un apartamento, 250. 
de esencias eternas y un relativismo insustancial, sin más orden ni medida que el fugaz aparecer de la finitud. Al primero correspondería una suerte de naturalismo ingenuo, cuya naturaleza aparece como factum inmediatamente dado y configurado por la eternidad; al segundo, un constructivismo igualmente ingenuo, cuyos constructos serían efecto de cada cultura y subjetividad particular.

La simplificación de este dualismo, además de insostenible, resulta inoperante frente a una realidad sumamente compleja, cuya multiplicidad efectiva exige modelos de pensamiento igualmente complejos, dinámicos, relacionales y policausales. El dualismo entre una naturaleza simplemente dada y una cultura meramente construida sienta las bases de todos los equívocos y falacias posmo-queer. Pero volvamos a Preciado. El dualismo excluyente que instala no deja alternativa. Su falsa opción antirrealista y relativista nos retrotrae al viejo régimen intelectualista de las representaciones abstractas, que se imaginan más allá lo eterno, más acá lo finito y plural. En términos neo-realistas, podríamos decir que Preciado ignora la dialéctica especulativa de los dos últimos siglos de pensamiento.

En el mismo sentido, el antiuniversalismo del autor imagina lo universal como una especie de abstracción genérica y necesaria, llamada a coincidir extrínsecamente con los particulares contingentes. Este tipo de representacionismo intelectualista, cuyo dualismo jamás responde ni por lo particular ni por lo universal, desconoce por principio la universalidad singular y concreta con la cual la dialéctica moderna superó los viejos cánones abstractos. La imposibilidad de pensar lo singular en la dialéctica inmanente de lo universal distorsiona la teoría política de Preciado, reduciéndola a micropolíticas moleculares, individualistas y relativistas. Los performances anti-universalistas, anti-científicas y relativistas del autor se oponen así

a políticas republicanas universalistas que conceden "reconocimiento" e imponen la "integración” de las "diferencias" en el seno de la República [...] 
Las políticas de las multitudes queer se oponen no solo a las instituciones políticas tradicionales que se creen soberanas y universalmente representativas, sino también a las epistemologías sexo-políticas hetero que aún dominan la producción de la ciencia. ${ }^{17}$

Dada la inhabilitación de toda política o racionalidad universal, la alternativa serán políticas identitarias de grupos o individuos que impongan su voluntad transgresora y sus deseos subjetivos, cuanto más poderosos, mejor. En caso de que estos grupos entren en conflicto de intereses, la solución quedará en manos del más fuerte. A falta de un criterio racional y universal, justicia y verdad son efectos del poder político-económico de turno, resultado — anti-edípico- de la maquinaria capitalista.

El nominalismo posmoderno considera que la ontología — vale decir, la caricatura del sustancialismo abstracto y dualista - constituye la superestructura ideológica de los sistemas políticos totalitarios, por una suerte de inferencia directa entre la totalidad metafísica y el totalitarismo político. La suposición posmoderna de un vínculo causal necesario - que por otra parte el propio relativismo posmoderno desmiente- entre el totalismo filosófico y el totalitarismo político ignora que, según la contrastación histórica, los supuestos filosóficos de los regímenes políticos totalitarios suelen ser el relativismo o positivismo evolucionista; por el contrario, habilitar presencias reales y absolutas suele legitimar la resistencia individual a poderes tiránicos. Como sostiene Žižek, la relación directa entre ontología y totalitarismo político dista mucho de ser evidente o estar demostrada, la historia mostraría la tesis opuesta. ${ }^{18}$

Otro supuesto del historicismo posmoderno consiste en identificar los modos de subjetivación con la subjetividad misma y las identificaciones

17 Paul B. Preciado, "Multitudes Queer: note pour une politique des anormaux", Multitudes núm. 12, vol. 2, (2003): 25, DOI: 10.3917/mult.012.0017.

18 Slavoj Žižek, El resto indivisible (Buenos Aires: Godot, 2016), 20. 
psico-afectivas y sociales con la identidad misma, de tal manera que el sujeto resulta ser, en última instancia, un epifenómeno del sistema que lo proyecta. Así considerado, no le cabe al sujeto ninguna instancia que escape al régimen de producción social y desde el cual sobreponerse a éste. Por el contrario, el sujeto agota las relaciones socio-históricas de las que emerge. Ésta es la principal tesis de Foucault, ${ }^{19}$ para quien la resistencia a los modos de ejercicio del poder se resuelve en la circularidad propia de los dispositivos políticos, como efecto de los mismos. La filosofía de Preciado asume las tesis foucaultianas respecto a la circularidad entre las relaciones de poder y la resistencia que éstas — se- ponen, de donde el antagonismo subjetivo pierde su autonomía para resolverse en una contingencia histórica de la opresión. Preciado no puede aspirar a otro modo de subversión que no sea la re-codificación de los flujos de producción socio-cultural o la reapropiación de las tecnologías de poder, como es el caso de su uso personal de testosterona sintética para su propia contrasexuación. ${ }^{20}$ La paradoja del nominalismo posmoderno consiste en la esencialización tácita de los regímenes socio-históricos contra los cuales nada puede hacerse más que resistir, parodiar o performar. Identificados con el sujeto, los dispositivos de poder se anticipan a cooptar toda práctica de resistencia y subversión. Las vanguardias contrasexuadas constituyen así meras acciones reactivas incapaces de superar los dispositivos que las engendran.

Pese a su intento explícitamente desontologizante de toda realidad, la filosofía de Preciado encubre una disimulada voluntad metafísica omniabarcante y monocausal. Su teorización pretende explicar toda realidad y verdad como funciones discursivas, efecto de la maquinaria de poder

Foucault, Historia de la sexualidad.

20 Recordemos que en Testo Yonqui el autor describe sus prácticas cotidianas de intoxicación voluntaria y auto-experimental con testosterona sintética, ponderadas por él como formas de disrupción. 
social. El lenguaje mismo es reducido a una supuesta e indemostrable función performativa, que por repetición produciría mágicamente todas las cosas. Los diversos campos de significación son, por su parte, retrotraídos al metasignificante socio-político del cual obtienen su contenido. En pocas palabras, realidad y verdad resultan funciones lingüísticas a cargo de los dispositivos parlantes de gestión androcéntrica y valor instrumental. Salvando las distancias históricas del caso, el nominalismo de Preciado no va mucho más allá del homo mensura del viejo relativismo sofístico, ayudado por los recursos de la big pharma y la high tech.

\section{La reducción de la diferencia sexual al constructo socio-discursivo}

Los supuestos desontologizantes y antirrealistas de Preciado interpretan la diferencia sexual en los términos de una construcción hetero-normativa, efecto de múltiples dispositivos y tecnologías de poder que apuntan a la reproducción de la especie y la acumulación privada del capital. En una palabra, la diferencia sexual es reducida a lo que la sociología feminista ha denominado "género" en el sentido de un ideal regulador de los comportamientos sociales. La reducción de la diferencia sexual a mera práctica discursiva está presente en la obra de Judith Butler, ${ }^{21}$ para quien el sexo expresa la coagulación material de determinadas relaciones históricas de poder. Para la filósofa americana, la diferencia sexual es tan arbitraria como la suma de configuraciones históricas y contingentes en las que hombres y mujeres han sido representados.

21 Ver Judith Butler, El género en disputa: El feminismo y la subversión de la identidad (Barcelona: Paidós, 2007); Cuerpos que importan: Sobre los límites materiales y discursivos del "sexo" (Barcelona: Paidós, 2002) y Deshacer el género (Barcelona: Paidós, 2004). 
Preciado coincide con Butler en que el género comporta "la herramienta teórica fundamental para conceptualizar la construcción social, la fabricación histórica y cultural de la diferencia sexual", ${ }^{22}$ así como en deconstruir la afirmación de la "feminidad" como un sustrato natural, una forma de verdad ontológica. Fiel al dualismo que lo inspira, Preciado opone como alternativas excluyentes o bien una supuesta naturaleza ontológica — cual esencia eterna e inmutable inmediatamente dada - o bien una construcción desontologizada y surgida ex nihilo de los dispositivos socio-culturales hegemónicos; respecto a este dualismo, él opta por un reduccionismo lingüisticista, encubiertamente metafísico, totalizante y mono-causal.

Uno de los clásicos argumentos que utilizan los teóricos queer, tanto Butler como Preciado, para erosionar el estatus ontológico de la diferencia sexual tiene que ver con el hecho de que existen corporalidades abyectas o anormales que no corresponden con la norma ni masculina ni femenina. De esta contingencia material se pretende derivar el carácter ficcional y político de la diferencia sexual. Pese a que el mismo hecho podría interpretarse en sentido contrario, como confirmación de la regla estadística, la teoría queer opta por inferir la inexistencia de la misma medida funcional que la sostiene. Los casos abyectos pondrían diferencia sexual y contrasexualidades en el mismo plano ficcional.

Tal como Preciado la entiende, no hay nada en la conceptualización de la diferencia sexual que no sea construcción, fabricación cultural, producción de género; de ello deriva una teorización centrada en los flujos indecidibles de identidades de género consistentes con las corrientes del poder político que las proyecta. Aquí reside uno de los grandes nudos argumentativos de las teorías queer: la reducción de la sexualidad a flujos

22 Preciado, "Multitudes", 20. 
de poder, sumada a la sustancialización o reificación de la categoría de género como una suerte de a priori socio-cultural que imprime cuerpos y subjetividades “de género". Las múltiples identidades de género reivindicadas por el activismo posmo-queer son combinatorias arbitrarias de significantes sexuales masculinos y femeninos.

La conversión de la diferencia e identidad sexual en género e identidad de género impresa extrínsecamente por la cultura supone el aminoramiento de la consistencia subjetiva, la pérdida de su dimensión inconsciente, la disociación de la unidad psico-somática, el rebajamiento del cuerpo a mera tabula rasa receptiva de significantes sociales. En palabras de Marta Lamas:

Con la sustitución del concepto de diferencia sexual por género se evitan conceptos como deseo e inconsciente y se simplifica el problema de la relación de lo social con lo psíquico. Esta incapacidad (¿resistencia?) para comprender el ámbito psíquico lleva a mucha gente a pensar que lo que está en juego primordialmente son los factores sociales. Aunque las personas están configuradas por la historia de su propia infancia, por las relaciones pasadas y presentes dentro de la familia y en la sociedad, las diferencias entre masculinidad y feminidad no provienen sólo del género, sino también de la diferencia sexual o sea, del inconsciente, de lo psíquico. ${ }^{23}$

Por otra parte, la asimilación del género a la identidad subjetiva supone la pérdida de la dimensión crítica de éste como herramienta de las ciencias sociales a los efectos de visibilizar y eliminar los estereotipos sexistas que subordinan a las mujeres. En lugar de desaparecer las relaciones de subordinación que el género supone, y liberar así la diferencia sexual,

23 Marta Lamas, "Usos, dificultades y posibilidades de la categoría 'género”, en El género. La construcción cultural de la diferencia sexual, Marta Lamas, ed. (Ciudad de México: PUEg, 2013), 353. 
las identidades de género eliminan la diferencia sexual y esencializan los estereotipos sexistas.

Valga recordar que el género fue introducido en la academia feminista de los años ochenta, en tanto categoría analítica de las formas bajo las cuales las sociedades simbolizan la diferencia sexual. Su principal mérito teórico fue deconstruir la supuesta objetividad, neutralidad y universalidad de los estereotipos sexuales hegemónicos, desenmascarando la operación política que los sostiene y explorando nuevas posibilidades de acción individual y colectiva. Sin embargo, en la medida en que el género absorbe y elimina las categorías de sexo y diferencia sexual, convirtiéndose en el fundamento socio-cultural de toda sexualidad y diferencia, la propia estructura de desigualdad que el género supone queda así consolidada. Varones y mujeres deben absorber como identidad la norma que los aliena, o bien, dejar de ser tales.

Desde la praxis política del feminismo, la desontologización de la diferencia sexual borra a las mujeres como sujetas políticas y jurídicas del feminismo, redefine la categoría mujer en los términos de un significante vacío, atribuible a todo sujeto parlante que se sienta profundamente tal, y la inter-secciona por incontables identidades sociales como las de raza, clase, etnia, edad, discapacidad, nacionalidad, estatus civil, trabajo, peso, altura, belleza, etcétera; de manera tal que es imposible distinguir a la mujer de cualquier otro significante social. La consecuencia más obvia de las políticas identitarias y su estrategia interseccional es la pulverización, guetificación y minorización de cualquier causa social, en especial la feminista, junto con la diseminación de los géneros en indecidibles combinaciones socio-culturales. Nuevamente aquí, la mera multiplicación, diferenciación extrínseca y combinatoria, libre de significantes sociales, desconoce la dialéctica estructural e inmanente a la realidad subjetiva y social y, en consecuencia, perpetúa el orden establecido. De otro modo, este tipo de fragmentación cultural es funcional a la lógica individualista del neoliberalismo y sus flujos de capital. 
En Changing Difference, Catherine Malabou denuncia "la violencia teórica de la desontologización de la mujer”, ${ }^{24}$ concomitante con su eliminación como sujeta política y jurídica. Malabou interpreta el antirrealismo queer y posfeminista como la última torsión en la historia de negaciones y sometimientos sufrida por las mujeres, pone en evidencia "la complicidad entre la violencia social y doméstica que rechaza dar a las mujeres un lugar y la violencia teórica que rehúsa dar a las mujeres una esencia”. ${ }^{25}$ La autora propone repensar la esencia ontológica de lo femenino en términos de un realismo material capaz de sostener la acción política del feminismo. Por supuesto, ella no considera aquí las esencias eternas e inmóviles figuradas por Preciado, sino una esencia plástica, reflexiva y dialéctica, tal como su ontología propone. Este tipo de esencialismo dinámico y abierto, característico de los nuevos y no tan nuevos realismos, es justo lo que el dualismo intelectualista de Preciado es incapaz de elaborar.

La negación desontologizante de las mujeres, que Malabou califica como violencia simbólica, constituye el sine qua non de las multitudes queer, la condición que permite a los relatos posmodernos eliminar a las mujeres como sujetas ontológicas, redefinirlas como significantes hetero-normativos, reificar los géneros y, a la postre, perpetuar la sujeción que su orden jerárquico supone, esta vez camuflado en la parodia.

\section{El proyecto de un transhumanismo poscuerpo}

La ficción desontologizada de la diferencia sexual es consistente con una innovadora teoría poscuerpo, en donde los somatecas fármaco-tecno-pro-

24 Catherine Malabou, Changing Difference. The Feminine and the Question of Philosophy (Cambridge: Polity Press, 2011), 99.

25 Malabou, Changing Difference, 96. 
ducidos reemplazan a los antiguos bio-cuerpos. A diferencia del cuerpo natural —instituido como pre-existente a la producción cultural—, los somatecas de Preciado no pre-existen sino que post-existen a las gestiones discursivas, científicas, tecnológicas, farmacológicas, económicas que los producen o transmutan. Los nuevos tecno-cuerpos se caracterizan no sólo por absorber pasivamente las marcas textuales del orden simbólico en turno, sino por ser objeto de una continua reinvención tecno-textual conforme los flujos de la maquinaria capitalista. Paradójicamente, se trata aquí tanto de un poscuerpo imaginariamente omnipotente, capaz de toda construcción, resistencia y transgresión, como de un somateca en realidad impotente, objeto de los más sofisticados dispositivos de poder, contrapoder y transpoder socio-cultural. Tal es el inevitable destino de un sujeto inscrito por el orden hegemónico.

La reducción del somateca a los regímenes de control, disciplinamiento y gestión política prosigue y profundiza la obra de Michel Foucault, cuya Historia de la sexualidad es en rigor la historia de los modos en que los regímenes socio-políticos modernos han controlado la sexualidad humana. Nada dice esa historia sobre la filogénesis, ontogénesis, evolución subjetiva o meta-psicología de la sexualidad. Al contrario, la historia mentada alude a los regímenes biopolíticos modernos, de los cuales habría nacido, según Foucault, la sexualidad. Asumidos los postulados foucaultianos, Preciado concluye que lo sexual son "productos, instrumentos, aparatos, trucos, prótesis, redes, aplicaciones, programas, conexiones, flujos de energía y de información, interrupciones e interruptores, llaves, leyes de circulación, fronteras, constreñimientos, diseños, lógicas, equipos, formatos, accidentes, detritos, mecanismos, usos, desvíos". ${ }^{26} \mathrm{El}$ sujeto de tales aparatos sexuales es un fabricador discursivo. 
Estamos ante una concepción claramente androcéntrica de la sexualidad, gestionada y operada por un homo faber postfreudiano, cuya materia prima será la potentia gaudendi. A diferencia del psicoanálisis clásico, para el cual la sexualidad es energía vital dada, arraigada en lo inconsciente e irreductible a la gestión volitiva y discursiva, la potentia gaudendi de Preciado es pura indeterminación determinable a voluntad. Preciado la caracteriza en estos términos:

No tiene género, no es ni femenina ni masculina, ni humana ni animal, ni animada ni inanimada, no se dirige primariamente ni a lo femenino ni a lo masculino, no conoce la diferencia entre heterosexualidad y homosexualidad, no diferencia entre el objeto y el sujeto, no sabe tampoco la diferencia entre ser excitado, excitar o excitarse con. No privilegia un órgano sobre otro: el pene no posee más fuerza orgásmica que la vagina el ojo o el dedo de un pie. La fuerza orgásmica es la suma de la potencialidad de excitación inherente a cada molécula viva. ${ }^{27}$

En breve, la potencia gaudendi emerge ex nibilo como posibilidad de todo goce y producción. Ella es capaz de darle a un dedo del pie tanta fuerza orgásmica como a la vagina o el dildo, porque todo es susceptible de devenir construcción contrasexual. En concreto, los goces de la potentia gaudendi son, entre otros, sadomasoquismo, fetichismo, fist-fucking, travestismo, post-porno, voyerismo, exhibicionismo, coprofilia, coprofagia, así como también hormonaciones cruzadas, intoxicaciones testoterónicas, obturaciones genitales, introducción de prótesis plásticas, flujos de sangre mutilada, flujos de siliconas, flujos digitales, flujos textuales, representativos, imaginarios, auto-percibidos, etcétera. Habrá que bus- 
car el goce específico de tales configuraciones, como vimos, más allá del principio del placer, en una voluntad de poder, control, apoderamiento y dominación omnipotente que ofrece esta absoluta indeterminación. La indeterminación pura de las moléculas gaudendi obedece a la omnipotencia contrasexual, sobre cuya indecidibilidad radical se montará el construccionismo no menos radical de los poscuerpos transgenéricos.

Esta voluntad de poder omnipotente nos devuelve a Foucault, puntualmente, a sus lecturas de Sade. En efecto, entendemos que las lecturas foucaultianas de Sade tienen gran influencia en la índole propia del goce contrasexual, ejercido más allá del principio del placer. Según Foucault, a través de la crueldad, la maldad y el libertinaje "Sade ha liberado el deseo de la subordinación a la verdad en la cual ha sido subsumido en nuestra civilización". ${ }^{28}$ El marqués tiene el mérito de haber liberado el deseo de la Verdad eterna y trascendente, para entregarlo a lo que podríamos llamar su propia voluntad inmanente, con la precisión de que dicha voluntad coincide con la crueldad y el libertinaje. "Para Sade, la conexión entre la verdad del deseo y la verdad sólo se alcanza en la búsqueda del crimen y el desorden permanente" ${ }^{29}$

A semejanza del individualismo queer, los libertinos de Sade son micropolíticos de su deseo individual. Para ellos "no hay un sistema general de libertinaje, sino que para cada libertino hay un sistema y esos sistemas definen la singularidad". ${ }^{30}$ Relativismo y subjetivismo resultan así plenamente consistentes con el neosadismo posmoderno. Sade revela el pulso secreto de este androcéntrico queer, la afirmación de la tortura, la violación, el abuso, la brutalidad y crueldad convertidos en "un lenguaje trans-

\footnotetext{
28 Michel Foucault, Language, Madness, and Desire. On Literature (Minneapolis: University of Minnesota Press, 2015), 146. Traducción de los autores.

29 Foucault, Language, Madness, 146. Traducción de los autores.

30 Foucault, Language, Madness, 139-40. Traducción de los autores.
} 
formador de desafío, discontinuidad y transgresión". ${ }^{31}$ De Sade a Foucault y de éste a Preciado, la arqueología contrasexual despunta su poder.

Detrás de las contrasexualidades de Preciado hay más voluntad de poder que deseo, placer o erotismo creador. Hay en ellas — para decirlo con Braidotti - una "fantasía de omnipotencia" narcisista aliada a "las fantasías de huida del cuerpo", ${ }^{32}$ que Preciado celebra como "el fin del cuerpo". ${ }^{33}$ Las fantasías omniconstructivistas de la ideología queer forman parte de la gran constelación transhumanista contemporánea, en donde deberíamos incluir no sólo las ficciones transgenéricas, sino también las transespecie, transobjeto, transedad, etcétera. La utopía transhumana, promovida por el relativismo posmoderno y patrocinada por el merchandising de Silicon Valley, sueña hoy con el control androcéntrico de todo simulacro y ficción.

Tal es, en definitiva, la última transgresión que la queerness nos promete. A saber, la de comprar, producir y vender nuestro propio somateca. Preciado es el profeta de esta nueva era farmacopornográfica, "en la que el mejor negocio es la producción de la especie misma, de su alma y de su cuerpo, de sus deseos y afectos [...] Consumimos aire, sueños, identidad, relación, alma" ${ }^{34}$

\section{La acción pospolítica de las multitudes queer}

Las multitudes queer son el emergente de una realidad desontologizada, fragmentada por representaciones ficticias y expuesta a una dispersión

31 Janice G. Raymond, A Passion for Friends. Toward a Philosophy of Female Affection (Melbourne: Spinifex, 2001), 46; también Jeffreys, Sheila, Unpacking Queer Politics. A Lesbian Feminist Perspective (Londres: Polity Press, 2003), 31. Traducción de los autores.

32 Rosi Braidotti, Metamorfosis. Hacia una teoría materialista del devenir (Madrid: Akal 2005), 322.

33 Preciado, Manifiesto, 20.

34 Preciado, Testo Yonqui, 44. 
transfinita indetenible, en líneas de fuga sin fin, ni proyecto, ni medida. Preciado opta por el concepto de "multitudes queer" ${ }^{35}$ como alternativa al dispositivo hetero-normativo, siguiendo el modelo de las multitudes contra el Imperio de Michael Hardt y Antonio Negri. ${ }^{36}$ Estas últimas proliferan indiscriminadamente e irrumpen de manera imprevisible siempre en los márgenes del sistema imperante. Las multitudes queer carecen de principio unificante u organicidad, de ellas no se espera ninguna revolución ni transformación estructural más que el continuo choque reactivo contra la hegemonía hetero-normativa. La democracia representativa, los derechos humanos universales y la narrativa científica son para ellas la expresión de una voluntad imperialista que busca oprimir a las minorías vulnerables.

En términos de agenciamiento pospolítico, la pregunta que cabe formular es sobre el alcance de lo abyecto como instancia emancipatoria. En la propuesta queer, la potencia de agenciamiento político de lo abyecto disputa a lo normal su poder significante hegemónico, por una operación de inversión de los opuestos. Las micropolíticas queer usurpan los discursos hegemónicos a fin de vaciarlos de sentido e invertirlos. En palabras de sus propios teóricos, la queerness "arrebata las armas al 'enemigo', se apropia de los conceptos elaborados para rendir cuentas de una supuesta entidad coherente y los relativiza hasta hacer de ellos útiles inservibles para la designación”. ${ }^{37}$ Sin embargo, ¿’logra este vaciamiento de significado desarmar la realidad heteronormativa? ¿Consigue con ello desembarazarse de la lógica representativa, dualista y sustancialista, de la que intenta escapar?

\footnotetext{
35 Preciado, "Multitudes".

36 Michael Hardt y Antonio Negri, Imperio (Massachussets: Harvard University Press, 2000).

37 David Córdoba, Javier Sáez, Paco Vidarte (eds.), Teoría Queer. Políticas bolleras, maricas, trans, mestizas (Barcelona: Egales, 2005), 169.
} 
Parecería que el gesto de reapropiación de las tecnologías de poder sigue remedando la estela del régimen de representación que quiere subvertir, recae en aquello que justamente pretende evitar, a saber, la conformación de un sujeto prístino, omnipotente, dotado de una razón instrumental y reproductor de los estereotipos de género, ahora bajo la figura psico-identitaria. En este sentido, Preciado no hace ningún honor a Butler, quien advierte sobre tal riesgo en las primeras páginas de Cuerpos que importan, cuando recuerda que volver a poner al sujeto humanista, voluntario e instrumental en el centro de un constructivismo radical sería errar el blanco. En otro sentido, Preciado ha superado todo proyecto humanista en virtud de su transhumanismo fármaco-tecnológico, y toda propuesta social en función de un postindividualismo cada vez más pulverizado en fragmentos identitarios.

Los cuerpos abyectos y disidentes se han emancipado de los dispositivos de control de la clínica médica, psiquiátrica, psicoanalítica, de la institución científica misma, y de todo discurso político que roce la universalidad de derechos, garantías y protecciones, incluyendo la propia Declaración Universal de los Derechos Humanos. Paradójicamente, se apropian de tales significantes para vaciarlos de contenidos y sujetarlos a la lógica psico-identitaria individual. En esta línea, las multitudes queer han encontrado la superación de la discriminación y estigmatización socio-cultural en la eliminación de lo real mismo, su conocimiento objetivo y su límite intrínseco, convertido ahora en ficción nominalista y relativismo psico-afectivo y micropolíticas de gestión identitaria.

De forma clara, las multitudes queer subsisten en el culto tácito del falo, parodiado como dildo, y la masculinidad hegemónica, simulada en una voluntad omnipotente y omnipene-tradora, tan potente que hasta se ha tragado a la mujer en su culto autoginefílico. Dildo y ano, puño y penetración —esos grandes fetiches de las contrasexualidades andróginas - hipostasían las fantasías más íntimas de Preciado, a saber, las de una erección, penetración y eyaculación infinita. María Isabel Peña 
Aguado lo explica de este modo: "un órgano tecno con una potencia y erección garantizadas y un cuerpo-ano siempre abierto, siempre pasivo, siempre dispuesto a ser penetrado. Lo irritante de este discurso es que además se nos presente como una salida a los binarismos que provienen de la heterosexualidad normativa". ${ }^{38}$ Lejos de superar el heterosexismo, las multitudes queer lo refuerzan.

Esto explica por qué Preciado es incapaz de idear otra transformación política más allá de las innovaciones endocrinológicas, cromosómicas y protésicas. En una impactante declaración, confiesa:

Lo que no es explicable hoy, en una situación en la que la inferioridad política de las mujeres se oculta tras una aparente igualdad legal, es por qué no hay una masa de bio-mujeres que trafican y consuman testosterona para acceder a la posición hegemónica. Quizá, simplemente, las bio-mujeres, no quieren el poder, prefieren seguir teniendo excusas para no triunfar, para no ganar dinero, para no tomar decisiones por sí mismas, para no dirigir los países que habitan, para no ser las únicas responsables de su placer sexual, de su mediocridad o su éxito. ${ }^{39}$

No podría expresarse con mayor rigurosidad la persistencia del falogocentrismo hegemónico como medida oculta de todo poder, potentia gaudendi y tecno-control. Lo específicamente innovador de Preciado y la queerness en general consistiría en la licuación y fragmentación de aquella misma hegemonía, ahora diseminada y travestida en configuraciones psico-identitarias de carácter privado. Si alguna vez — para el feminismo- lo personal fue político, ahora — para la queernes - toda política es personal y subjetiva.

38 María Isabel Peńa Aguado, "Cuerpo indeterminado: la precariedad del cuerpo en el discurso feminista”, Revista de la Academia 20 (2015): 62.

39 Preciado, Testo Yonqui, 154. 
En la medida en que el sujeto es efecto inmanente y circular de los dispositivos de poder, no hay alternativa de escape ni posibilidad real de constituir al sujeto individual superador e irreducible. El homo sexo-faber de Preciado no tiene otra perspectiva emancipatoria que la de su íntimo agenciamiento contrasexual. Su máxima pospolítica reza: "el que quiera ser sujeto de lo político, que empiece por ser rata de su propio laboratorio". ${ }^{40}$ No se trata en absoluto de una propuesta anticapitalista, sino de un capitalismo que ha llevado al extremo la lógica individualista y autónoma. El agente pospolítico se parece mucho al trabajador del régimen postindustrial y farmacopornográfico, productor de somatecas y goces transhumanos: un sujeto híbrido, hormonado, manager de una vida que ha sido puesta en venta.

En última instancia, y como para paliar la hegemonía política del imperio, el proyecto postpolítico de Preciado se desliza hacia una suerte de salvacionismo religioso, que es en el fondo su más auténtica identificación subversiva. A falta de transformaciones estructurales, valga el consuelo místico que aporta la testosterona sintética. En efecto, las intoxicaciones voluntarias de Preciado performan sus trances chamánicos hacia la transustancialización cósmica. De este modo, la iniciación queer nos invita al viaje más allá del bio-cuerpo, hacia un somateca universal. La postrera confesión del autor declara: “'mi’ cuerpo está más allá de 'mi’ piel, en un lugar que no puede ser pensado simplemente como mío", "mi cuerpo no existe", porque en realidad "no tengo alma, ni cuerpo. Soy el cosmos". ${ }^{41}$ En esta suerte de fusión mística universal, la teoría poscuerpo de Preciado manifiesta su profunda y secreta fe: la de una ficción universal y totalizadora que lo abraza todo, y cuya revelación él nos anuncia.

$40 \quad$ Preciado, Testo Yonqui, 248.

41 Preciado, Un apartamento, 169, 216, 28. 


\section{A modo de conclusión}

La propuesta metafísica de Paul B. Preciado constituye uno de los mejores ejemplos de una postmodernidad entregada a sus propios fantasmas, transustanciaciones y secretas revelaciones. Su narrativa expresa el punto de llegada de lo real convertido en reality show, de la verdad devenida función discursiva, del deseo individual erigido en derecho público, y de la política convertida en grupos de intereses y presión. Lo serio del caso es que la ficción se hace realidad con mucha más violencia que la de sus espectros y fantasmas.

La única justificación teórica a este antirrealismo desontologizante son sus propias ficciones, falacias y equívocos. Además de su voluntad de poder metafísico, decidida a explicarlo todo por una monocausalidad sociopolítica que en definitiva siempre queda más allá, en algún lugar indemostrado, cósmico, abisal. El rédito económico-político de mantener este tipo de dualismo intelectualista como falsa alternativa entre el universo de idealidades eternas y el mundo de particulares contingentes es, justamente, el de forzar la elección hacia un relativismo individualista cada vez más fragmentado. En tales términos, la ideología posmoderna opera hoy la agenda cultural del neoliberalismo. Su constructivismo radical y su proyecto transhumano justifican las consignas subjetivistas y micro-moleculares del capitalismo tardío. La propuesta de Preciado no puede pensarse más allá de la lógica del mercado, donde los deseos personales son comprendidos como epifenómenos sociales. Su prédica política contrasexual no es sino la actualización de la maquinaria capitalista.

Respecto al proyecto feminista — de suyo universal y estructural—, la desontologización de la diferencia sexual, contracara de la esencialización de los estereotipos de género, abona la indetenible reproducción de estos últimos bajo la innovadora modalidad psico-indentitaria. La privacidad e indecidibilidad de las identidades de género se esgrime como justifica- 
ción subjetivista para la conservación de comportamientos, poses y roles sexistas, violentos y discriminatorios contra las mujeres. En este sentido, las multitudes queer son esencialmente conservadoras y reaccionarias. Sus performances, lejos de transformar algo, constituyen "una categoría reactiva que se ve a sí misma en oposición a la norma establecida”. ${ }^{42}$ Ellas reaccionan contra la norma, pero reaccionar no es accionar, transgredir no es transformar, proliferar y recombinar no es crear. Más allá del show, la queerness nos revela su impotencia.

Detrás de la fantasía omnipotente de ser el cosmos y tener entre manos el poder de crear todas las cosas, detrás de ese narcisismo imaginario asoma Tánatos como la última verdad contrasexual. Más allá del placer, está el goce de la muerte. Los propios estetas queer confirman la analogía entre la queerness y la pulsión de muerte: "me parece ver en todo ello una herencia lejana o muy cercana de lo que supuso la introducción por parte de Freud de la pulsión de muerte... lo siniestro, lo ominoso, el esquizofrénico". ${ }^{43} \mathrm{Al}$ Eros_creador se opone así un goce desligado cuya reacción es permanente destrucción, choque, erosión y vaciamiento de todo sentido humano.

La pérdida de sentido de lo real, devenida agenciamiento político, desemboca inexorablemente a una necrosis cultural, elucubradora de fantasmas. El imaginario tecnoteratológico de la postmodernidad tardía, sus ciber-subjetividades y somatecas farmacopornografiados son síntomas de un imposible: desligarse de la condición humana, finita y mortal. Ligarse a ella, afirmarla y sostenerla en su herida y fugacidad son función de Eros, pulsión de vida, sexualidad y su diferencia.

42 Elizabeth Grosz, Space Time, and Perversion. Essays on the Politics of Bodies (Nueva York y Londres: Routledge, 1995), 219. Traducción de los autores.

43 Córdoba, Sáez y Vidarte, Teoría Queer, 93-94. 


\section{Referencias}

Alaimo, Stacy y Hekman, Susan, eds. Material Feminisms. Bloomington: Indiana University Press, 2008.

Braidotti, Rosi. Metamorfosis. Hacia una teoría materialista del devenir. Madrid: Akal 2005.

Butler, Judith. El género en disputa: El feminismo y la subversión de la identidad. Barcelona: Paidós, 2007.

. Cuerpos que importan: Sobre los límites materiales y discursivos del "sexo". Barcelona: Paidós, 2002.

. Deshacer el género. Barcelona: Paidós, 2004.

Córdoba, David, Javier Sáez y Paco Vidarte, ed. Teoría Queer. Políticas bolleras, maricas, trans, mestizas. Barcelona: Egales, 2005.

Deleuze, Gilles y Félix Guattari. El Anti-Edipo. Capitalismo y esquizofrenia. Barcelona: Paidós, 2004.

Foucault, Michel. Language, Madness, and Desire. On Literature. Minneapolis: University of Minnesota Press, 2015.

. Historia de la sexualidad. La voluntad de saber. Buenos Aires: Siglo xxi Editores, 2014.

Grosz, Elizabeth. Space Time, and Perversion. Essays on the Politics of Bodies. Nueva York y Londres: Routledge, 1995.

Hardt, Michael y Antonio Negri. Imperio. Massachussets: Harvard University Press, 2000.

Hocquenghem, Guy. El deseo homosexual. Madrid: Melusina, 2009.

Jeffreys, Sheila. Unpacking Queer Politics. A Lesbian Feminist Perspective. Londres: Polity Press, 2003.

Lamas, Marta. "Usos, dificultades y posibilidades de la categoría 'género"”. En El género. La construcción cultural de la diferencia sexual, editado por Marta Lamas. Ciudad de México: Pueg, 2013.

Malabou, Catherine. Changing Difference. The Feminine and the Question of Philosophy. Cambridge: Polity Press, 2011.

Marcuse, Herbert. Eros y civilización. Madrid: Sarpe, 1983. 
Peña Aguado, María Isabel. "Cuerpo indeterminado: la precariedad del cuerpo en el discurso feminista”. Revista de la Academia 20 (2015): 47-65.

Preciado, Paul B. Un apartamento en Urano. Crónicas del cruce. Barcelona: Anagrama 2019.

. Testo Yonqui. Madrid: Espasa Calpe, 2008.

- "Multitudes Queer: note pour une politique des anormaux". Multitudes núm. 12, vol. 2 (2003): 17-25. DOI: 10.3917/ mult.012.0017

. Manifiesto contrasexual. Prácticas subversivas de identidad sexual. Madrid: Opera Prima, 2002.

Raymond, Janice G. A Passion for Friends. Toward a Philosophy of Female Affection. Melbourne: Spinifex, 2001.

Sáez, Javier. Teoría queer y psicoanálisis. Madrid: Editorial Síntesis, 2004. Žižek, Slavoj. El resto indivisible. Buenos Aires: Godot, 2016. 